\title{
El valor político de la educación en Kant
}

\begin{abstract}
Antonio Hermosa Andújar*
Resumen: El discurso educativo kantiano aspira a transformar al educando en un sujeto libre en grado de controlar racionalmente sus pasiones. Se inserta así en la fase actual de su filosofía de la historia, cuando la razón ha sustituido a la naturaleza en la tarea de organizar racionalmente la convivencia humana en base a la libertad. Sin embargo, de este modo, por un lado nos encontramos con la contradicción de que la educación puede conformar ya, en el presente, los sujetos que la historia habría de conformar en el futuro; y, por otro, con la consecuencia fuertemente autoritaria de que una educación como ésa, de generalizarse, incurriría en la paradoja de eliminar del mapa social a la propia política, a cuya disposición se había puesto a fin de establecer la libertad en la sociedad.
\end{abstract}

Palabras clave: Educación. Kant. Libertad. Platonismo. Razón.

\section{O valor político da educação para Kant}

Resumo: O discurso de Kant sobre educação visa transformar o educando em um indivíduo livre capaz de racionalmente controlar suas paixões. Se coloca assim na fase de sua filosofia da história, quando a razão substituiu a natureza na tarefa de, racionalmente, organizar a convivência humana baseada na liberdade. No entanto, desta forma, por um lado, encontramos a contradição de que a educação pode forjar, no presente, os sujeitos que a história forjaria no futuro, e, por outro, com a consequência fortemente autoritária de que tal educação, ao generalizar-se, incorreria no paradoxo de eliminar do mapa social a própria política, quando em tese seu propósito seria o de estar a disposição dela para estabelecer a liberdade na sociedade.

Palavras-chave: Educação. Kant. Liberdade. Platonismo. Razão.

Doutor em Filosofia pela Universidad Nacional de Educación a Distancia (UNED). Professor Titular do Departamento de Estética e Historia de la Filosofia da Universidade de Servilha/Espanha.E-mail: hermosa@us.es. 


\title{
The political value of education in Kant
}

\begin{abstract}
In his discourse on education, Kant seeks to transform the educand into a free subject capable of rationally controlling her own passions. Thus, this discourse belongs to the current phase of its intellectual history, that is, when reason has replaced nature in the task of rationally organising human coexistence on the foundations of freedom. However, this results in a twofold paradox. On one hand we encounter the contradiction that education is capable of shaping now, in the present, the subject that history would have shaped in the future. On the other, there is the strongly authoritarian consequence that, were such an education to prevail, it would result in the paradox of eliminating politics itself from the social map, whose very service it had devoted itself to in order to establish freedom in society.
\end{abstract}

Keywords: Education. Kant. Freedom. Platonism. Reason.

\section{Educación y Filosofía de la historia}

En 1784 Kant veía en su época una proliferación de "prodigios"1 que le inducía al optimismo, y la siguió viendo así prácticamente hasta el final de sus días, traspasado ya el umbral del siglo XIX. Ciertamente, no se engañaba sobre ella, razón por la cual la pregunta de si era la suya una "época ilustrada" se saldaba con un seco no; empero, a continuación edulcoraba la respuesta con un matiz aleccionador: era "sí una época de ilustración". Y ello no era baladí. Porque una época que se ilustra está dejando de ser un rebaño de siervos, culpables de complacerse en su minoría de edad, para empezar cada sujeto a hacer uso personal de su razón, el instrumento de su liberación individual y el sello de su digni-

1 Uno de ellos, y no el menor, era que en su propia sociedad un rey, nada menos que un rey, fuera filósofo; otro, su causa, esto es, la difusión del movimiento ilustrado (KANT, 2009). Más tarde descubrirá otros nuevos, como "la simpatía rayana en el entusiasmo" de la especie docta entre los humanos, garantía del ideal que vendrá ("Replanteamiento de la cuestión sobre si el género se halla en continuo progreso hacia mejor", en op. cit., pp. 201-202). Y ninguno de ellos tendrá que ver con la imaginación, que es de las facultades del espíritu la más fértil en los mismos (KANT, 1981, p. 130). 
dad. Es ese el tipo de individuos con el que la naturaleza asegurará la culminación de sus planes de libertad en relación con el género humano.

El adulto que por "pereza y cobardía" aspira a perpetuarse como niño, vegetando desde un punto de vista moral a la sombra del dictado de arbitrios terceros y ajeno a cuanto entrañe responsabilidad, con la ilustración crece hasta convertirse en hombre hecho y derecho; un hombre que se emancipa de tutores antiguos y nuevos, sabedor de que el prejuicio ataca incluso a quienes lo cultivan; que reivindica para sí el deber de la crítica y lo ejerce contra supersticiones y prejuicios, contra todo tipo de oscurantismo y sus pastores, y en general contra toda autoridad fundada en la sinrazón o la fuerza. El sujeto racional y responsable es el sujeto ilustrado al que la naturaleza y la historia antes, y la libertad ahora, le han ordenado progresar indefinidamente, hasta que llegue a construir un mundo en paz, esto es, compuesto de sociedades civiles republicanas pobladas de individuos cosmopolitas: el genuino fin de la historia, el “fin supremo de la cultura" (KANT, 2009, p. 86).

Lograrlo, con todo, no le será fácil, pues ni la naturaleza general, ni la suya propia, y ninguna otra fuerza externa, lo han pertrechado para esa misión. Todo él ha sido hasta ahora obra suya; su entera historia le pertenece, aunque la violencia y otros dioses hayan forzado ocasionalmente a un aprendizaje mecánico que cubría con su velo de azar sus genuinos intereses y sus más profundas necesidades. Y para el futuro no le cabe esperar otra cosa: la naturaleza se obstina en sacar de él las herramientas con las cuales labrar su felicidad. Al igual que antaño lo forzó a curtir su propia razón a través del ensayo, el ejercicio o el aprendizaje; a fabricar la benevolencia que le distingue, como también a procurarse su alimento, su refugio, su seguridad, sus placeres, su inteligencia o su astucia, hoy lo constriñe, mediante una razón ya sumamente perfeccionada aunque todavía imperfecta, a modelar su felicidad de acuerdo con los designios establecidos por ella. ${ }^{2}$

2 Idea, p. 36 (así, se sale de la naturaleza sin dejar de ser natural; como se saldrá asimismo 
El esquema de todo ese movimiento histórico conduce desde la barbarie y la violencia hasta la libertad y la paz, los polos de la filosofía de la historia de Kant. En su fase actual, y ya para siempre, la razón porta la antorcha de la libertad y sigue su estela normativa. ${ }^{3}$ El concepto de deber, que preside la acción racional en los ámbitos de la moral y del derecho público, constituye el nexo de unión entre ambas potencias del sujeto (HERMOSA ANDÚJAR, 2012). Es en este punto donde el opúsculo kantiano sobre la educación se incrusta en el corazón mismo de su filosofía de la historia.

El proceso educativo, analizado por dentro, duplica a su modo el proceso filosófico-histórico en el que se enmarca, cuyo fin refuerza si se le considera en cambio como un elemento autónomo más en el interior del mismo. Lo duplica a su modo, decíamos, al concentrar en cada educando el proceso histórico, pues también él debe guiar al sujeto desde la potencial barbarie, en la que caería si se renuncia a educarlo ya desde la cuna, hasta la vida racional y libre pasando por la cultura; o, también, cuando fija -una obsesión de los pedagogos desde Plutarco ${ }^{4}$ - en la elección del educador uno de los hitos del proceso educativo, par a como lo es la elección del Herr, y aun la del filósofo (KANT, 2009), en el proceso filosófico-histórico. ${ }^{5}$ Incluso la definición de barbarie como "independencia respecto de las leyes" ${ }^{96}$ subraya los paralelismos de ambos esquemas evolutivos. ${ }^{7}$

tanto por su carácter técnico, herencia de Prometeo, como por su tendencia a individualizarse aislándose. Aristóteles y Maquiavelo habían precedido a Kant en sacar la legalidad humana de la natural aun manteniendo el reino del hombre dentro de la naturaleza).

3 En realidad nunca ha dejado "de tender hacia la libertad", nos dice Kant (2009) en ¿Qué es Ilustración?, como afirma D. Innerarity (1987, p. 57).

4 Aunque en Plutarco (2002) la labor del instructor kantiano ya la lleva a cabo el pedagogo: Sobre la educación de los hijos, cap. 7-A.

5 Proceso en el que se completa con la figura del legislador, como es el caso de Licurgo o Solón, pero también de Platón, Maquiavelo o Rousseau.

6 Über Pädagogik [en "Kants gesammelte Schriften”, Berlin, Königlichen Preussischen Akademie der Wissenschaften, 1902 y ss, Band IX, pp. 437-499]; citamos sin embargo por la edición española KANT (2013, p. 30).

7 Tales paralelismos distan de concluirse aquí, como se constata en el hecho de que ambos proceden de ideas, en la cuestión del orden en el que actuar, etc. 
Mas también lo refuerza. Al punto que, según vemos ahora, sin el nuevo elemento particular introducido, esto es, la educación, difícilmente el general habría resultado exitoso, y la razón habría dejado insatisfechas las demandas de la libertad. De hecho, la educación era el gran ausente del discurso de la paz mantenido en las obras iniciales, y lo siguió siendo hasta casi al final; en la Idea ..., la razón se bastaba y sobraba para coger las riendas de la humanidad y conducirla por la senda de un progreso irreversible hasta donde el sueño de la razón, tan contrario al goyesco, produce libertad. Haciendo acopio de experiencias y acumulando saberes nuevos con los que reinterpretarlas había llegado a la luminosa conclusión de que la violencia se había erguido contra su naturaleza en una causa ${ }^{8}$ moral, puesto que incitaba a la razón a hacer lo contrario a fin de cancelar su presencia de la historia profética que el género humano - el profeta en cuestión - estaba por hacer; había agradecido a la naturaleza la insociable sociabilidad con la que sella a sus criaturas antropomorfas, y el sabio antagonismo que ésta produce, pues también así surge una nueva causa del derecho y de la paz. De otro lado, una razón ya experimentada en su propio auto-conocimiento había redescubierto en algunas de sus ideas conceptos puros de su dimensión práctica, como el de "elaborar una historia universal conforme a un plan de la naturaleza" (KANT, 2013, p. 47) tendente a la unión de todas las naciones, del que se convierte además en profecía; o bien el de "una constitución en consonancia con el derecho natural de los hombres, a saber, que quienes obedecen la ley deben ser simultáneamente colegisladores" (KANT, 2013,p. 207), la cual materializaría la unidad aspirada por la idea anterior: y ambas posibles de puro necesarias.

En este último texto, en el cual patrocina la defensa del progreso constante del género humano, datado en 1798, Kant ya alude ciertamente a la "Ilustración de un pueblo", pero limita la misma a "los derechos y deberes respecto del Estado al que pertenece”, un alegato en contra del

8 Como se ve, se trata de causas por reacción, no de una causalidad mecánica. 
autoritarismo de los gobernantes y en pro de los derechos de los pueblos, así como un auto-homenaje a la casta de los filósofos, ${ }^{9}$ sus osados defensores, pero sin alusión alguna a la educación stricto sensu. Y lo más paradójico de todo: dicha alusión aparece justamente, en su cabal planteamiento y en la plenitud de su significado, dos parágrafos después (KANT, 2013, p. 209), pero justo para ser rechazada; bien es verdad que el motivo del rechazo no es intrínseco, sino el, llamémosle así, crudo realismo de Kant, que denuncia tanto el desinterés del "pueblo" por tal educación, cuanto el interés del príncipe por gastar básicamente en la guerra, como también la anarquía propia de las instituciones educativas.

Con todo, la situación en nada habrá cambiado cuando apenas algún año después ese programa se incorpore de pleno derecho al núcleo del proyecto ilustrado, al punto de impedir la epifanía de la libertad sin su presencia. ${ }^{10}$ Para entonces la razón pura práctica habrá extraído una idea más de su cartera metafísica a fin de legitimar la llegada del advenedi$z o$ a la ciudad del futuro. La calificación de la educación ahora como adalid del progreso y su nombramiento como un sujeto más del proceso libertario, a pesar de lo sostenido unos años atrás, apunta al aumento del pesimismo kantiano respecto de la acción a favor del progreso de los poderes públicos y aun de las grandes inteligencias, depositarias antes de sus esperanzas; pesimismo que intenta disimular como una lección de paciencia, es decir, abandonándose en los brazos del tiempo y fiando a un horizonte más indeterminado aún que el ápeiron de Anaximandro el progresivo advenimiento del nuevo mundo republicano y cosmopolita.

¿Cuál será el papel reservado a la educación en dicho proceso, qué cambios introduce su presencia en el mismo?

Si la libertad en un mundo integrado por sociedades civiles republicanas administradas por el derecho constituye el fin de la historia; y

9 Bien que, ciertamente, no a la Platón, como tampoco a la Max Weber, por cierto.

10 Incluso ya existía, desde 1774, el Instituto Filantropinum de Dessau, sobre el que escribiría un artículo dos años después. 
si su medio es la ilustración, que forja sujetos titulares de derechos y en grado de servirse autónomamente de su razón, entre quienes descuellan los doctos que hacen uso público de la suya ante ellos, la educación aparece como el recurso por excelencia del medio, esto es, el instrumento que hace posible a tales sujetos $\mathrm{y}$, con ello, potencialmente reales los sueños de la razón.

Si con la educación se pretende construir un ideal, un tiempo en el que "aún no" se vive (KANT, 2013, p. 39), el tiempo de la educación habrá de ser por fuerza el futuro. La crítica que a partir del desconocimiento de semejante ley pedagógica dirige tanto a los padres como a los príncipes alumbra sobre todo la convicción de que en el ámbito de la educación casi todo está por descubrir. Y que "la idea de Humanidad y su completo destino" (KANT, 2013, p. 36), nunca producirá su fruto en la tierra en tanto la mira de unos y otros se detenga a ras de suelo: la de los padres, al nivel del mero bienestar material de sus vástagos; la de los príncipes, donde los súbditos son sólo carnaza con la que conseguir sus deseos.

La educación, en cambio, es mucho más y, en realidad, tiene sin duda algo que ver con la miopía de los padres, mas nada en cambio con la tiranía de los príncipes. Desde que Locke revolucionara dicho mundo transformando al individuo en general, y al educando en particular, en una tabula rasa; desde que la mente en blanco del mismo reasignara a la pedagogía nuevas tareas y contenidos dado que ahora se hallaba ante una sustancia enteramente maleable, construir un individuo era un acto de creación y la educación era precisamente el creador. ${ }^{11}$ El propio Lo-

11 Era una revolución porque suprimía la transmisión hereditaria de las cualidades nobles, introducía igualdad, capacitaba a los sujetos para cualquier contenido, daba del niño una visión realista, en contraposición a la idealización traída posteriormente por el romanticismo, etc. Con todo, los prejuicios tenían fuerza suficiente para introducir desde fuera lo que habían quitado de dentro. Así, la función primaria de la educación consistiría en "el desarrollo de criaturas racionales responsables, en grado de cumplir con sus deberes cristianos" (PORTER, 2001, p. 342). También Kant modelará su tabula rasa (en el fondo, la idea no es tan nueva, puesto que pertenece a Plutarco, una vez más. En su célebre opúsculo educativo, cierto, nos dice que la "virtud", el efecto de la buena educación, 
cke nos dice que "nueve de cada diez son lo que son, buenos o malos, útiles o inútiles, gracias a su educación. Es ella el artífice de la mayor diferencia en la humanidad" (PORTER, 2012, p. 340). También Kant querrá con ella fundar un carácter, pues si bien la educación empieza con la vida lo que en realidad cuenta es básicamente la formación moral del educando. Aun así, no duda en señalar que "únicamente por la educación el hombre puede llegar a ser hombre. Aquél no es sino lo que la educación le hace ser" (KANT, 2013, p. 31). Con este supuesto en la mano, la razón intentará llevar al educando, no adonde quieran sus padres o sus príncipes, ni adonde quiera su naturaleza, sino adonde quiere ella misma guiada por la libertad: hacia el futuro, vale decir, hacia la realización de la humanidad en su persona - su consagración como fin en sí - y hacia la cooperación con los demás para realizar juntos el destino común de la Humanidad, ya que éste no puede actuarse en un único individuo, sino en el conjunto de la espécie. ${ }^{12}$

Educar para el futuro sólo es posible, afirma Kant, porque la educación es un arte. Su materia son los "muchos gérmenes" (KANT, 2013, p. 33) que pueblan la condición humana y su sujeto son las muchas generaciones que a lo largo del tiempo plantan y cosechan esas semillas, las de nuestras "disposiciones naturales", y van moldeando la infinidad de individuos en que se atomizan a la vez que preparan así indefinidamente el terreno para que la Humanidad vaya desplegando sin tregua su destino, "pues tras la educación está el gran secreto de la perfección

requiere tres cosas: "naturaleza, razón y costumbre"; pero cuando acto seguido procede a delimitar la función de cada una claramente se percibe que la educación puede llegar incluso a corregir la naturaleza; op. cit., art. 4A-C).

12 No deja de ser llamativa, por decirlo con suavidad, una doctrina que considera al sujeto individual como fin en sí, y por tanto un deber para sus autoridades naturales y políticas, y sin embargo lo incluye como una pieza más en el destino de la humanidad, siempre ajeno a él al ser un hecho colectivo; de una doctrina, además, que cifra en ese ideal de la razón también el sueño de la Naturaleza, y sin embargo fuerza -mediante la educación, justamente - al sujeto a dejar en el camino a determinados elementos naturales constitutivos, como las pasiones. La maldición de Platón o Aristóteles tenía la sombra muy alargada, como se ve. 
de la naturaleza humana" (KANT, 2013, p. 32). ${ }^{13}$ Cada generación acumula en sí el tesoro anterior, añade su cuota proporcional al mismo, y el hombre es singularmente un ser crecientemente moral que convive con sus semejantes en una sociedad y un mundo cada vez más y mejor reglados por el derecho. Lo que aquí cobra forma, por tanto, lo que aquí se crea, no es sólo el individuo, sino también el propio género humano.

La educación es un arte porque tras ella hay un "plan", vale decir, una idea y su - intento de - encarnación práctica. Nuestra época, asevera Kant, que ya heredó de Platón ideas más perfectas que la realidad de la que son modelo, y que las ha rematado a su vez hasta extraer del perfeccionamiento de su propia configuración interna la garantía de su realización, tiene por ello in mente "el proyecto de una teoría de la educación" con la que dar forma a sus disposiciones naturales. En lugar de dejar que el azar gobierne las circunstancias de manera mecánica e imparta graciosamente lecciones de utilidad o inutilidad al hombre, éste prefiere desarrollar una técnica "razonada" de aprendizaje de la que deducir lecciones precisas de racionalidad y moralidad. Al respecto, lo que la teoría le aconseja, es decir, lo que desde la cantera inagotable de la razón práctica se le prescribe, es institucionalizar el proyecto educativo antedicho en una "disciplina”, la Pedagogía, a partir de la cual unificar la anarquía de las lecciones en una enseñanza única y metódica. La moral se apoyará en la nueva institución para garantizarse su presencia en el mundo, repartiendo a través de la misma sus beneficios a cada educando, esto es, haciéndolo mejor persona cada vez (KANT, 2013).

Una consecuencia inmediata de dicha institucionalización es la solución de uno de los enigmas más acuciantes del proceso educativo, que lo traía en jaque a nivel particular como su versión más general ponía en jaque al progreso de la historia, a saber: el de establecer el punto de partida del mismo, esto es, el de individuar a partir de qué sujeto, si el príncipe o

13 Un "secreto" que, sin embargo, permanecerá en parte eternamente velado, habida cuenta de que la perfección, en su grado último, no es alcanzable por el hombre. 
los súbditos, debía tomar forma. Mucho tendrían que cambiar las cosas, añade Kant, para que la educación pública se halle en condiciones de hacerse cargo de una educación como la requerida, porque debe cambiar tanto el contenido de la misma como el de la función de la política. Ahora se ve que tampoco los padres por sí mismos deben completar la educación moral de sus vástagos, sino que deben fiarla a los - pocos, especifica Kant - "institutos de educación” (privados, básicamente) que deben empezar a salpicar el país. Ellas serán las que produzcan las élites a partir de la cual la moralidad se expanda como una mancha de aceite por el conjunto de la sociedade. ${ }^{14}$

Se comprende fácilmente tras la descripción de las dificultades a solventar por el discurso pedagógico en la realización de su tarea la dramática apostilla de su autor: "la educación es el problema más grande y difícil que puede ser propuesto al hombre" (KANT, 2013, p. 34). Palabras en parte idénticas, añadamos, a las otrora utilizadas en la formulación del sexto principio de la Idea: "Este problema (a saber: "la instauración de una sociedad civil que administre universalmente el derecho", explicitado en el quinto principio) es al mismo tiempo el más difícil y el que más tarde será resuelto por la especie humana" (KANT, 2009, p. 40). Entre una afirmación y otra queda tan patente la ausencia de la educación como temática específica de la filosofía de la historia, esto es, su irrelevante papel para el destino político, como su estelar irrupción en dicho ámbito casi dos décadas después. Con todo, la política recupera de inmediato su lugar en el trono, bien que ahora lo comparte con el nuevo monarca: "El hombre puede considerar como los dos descubrimientos más difíciles el arte del gobierno y el de la educación" (KANT, 2013, p. $35)$. Se lo ha ganado a pulso porque, en realidad, lo que más dificultaba

14 Cómo esto se logre, en cambio, no es algo ni que Kant especifique ni que se deduzca con facilidad de su razonamiento. Más bien lo contrario. Las nuevas élites se parecerán demasiado a las élites que ya gobernaban la sociedad civil republicana, donde el principio de la ciudadanía marginaba a la gran mayoría de la población, titular sólo de los de libertad e igualdad, del ámbito público (p. 41). 
la instauración de un mundo republicano era ante todo la necesidad de un "señor", pues siendo humano como es, y estando situado al otro lado de la ley, debía ser el mejor educado de todos, el nuevo Ciro de un nuevo Jenofonte, y aun así difícilmente habría dejado de abusar de su poder. Como ya explicara Aristóteles, sin control político mal puede un gobernante contener la maldad que todo hombre lleva dentro. En cambio, merced a la educación, dicho problema se ha esfumado por sí mismo y de la poderosa amenaza anterior no queda ahora ni su recuerdo.

\section{¿Educación o Política?}

El proceso educativo según Kant lo concibe aparece todo él dominado por una fuerte impronta moral; ${ }^{15}$ no sólo se subdivide en cuidados y formación (KANT, 2013, p. 40), sino que ésta se lleva la cabeza y el cuerpo del león dejando para aquélla la cola del ratón. La primera está protagonizada por padres, nodrizas o niñeras, pero la genuina maestra es la naturaleza, que impone a cualesquiera de los sujetos recién mentados una acción que en nada turbe su curso en el niño; su principio rector es "que el niño no se acostumbre a nada", por cuanto la costumbre es una maga que rápidamente crea "necesidad" (KANT, 2013, p. 49-54), y una vez creada la naturaleza ya no podrá jugar con él cuando quiera. El máximo celo de sus cuidadores, en suma, debe consistir en evitar que el niño se procure daño al hacer algo; y es ese el motivo por el cual Kant la considera "negativa". ${ }^{16}$

Parecería raro encontrar una sombra de moralidad en un ambiente tan físico; empero, cuando Kant añade los colores al cuadro este no deja

15 Y su moralidad por una impronta arqueológica-platónica -, de la que su reto de prohibir las pasiones del individuo a fin de garantizar el éxito de la razón sobre su conducta es sin duda su momento álgido.

16 Ese momento roussoniano de la pedagogía kantiana, que el ilustre Citoyen de Génève despliega tanto en su obra cumbre pedagógica, el Emilio, como en el capítulo al respecto de sus Consideraciones sobre el Gobierno de Polonia, es demasiado conocido como para insistir más en ello. 
de adquirir tonalidades sombrías; así, por ejemplo, aun cuando el niño sea aún amoral, si se le deja adquirir hábitos se volverá menesteroso en lugar de libre, pues el repetirse de una acción, lejos de ser inocente, la hace recrearse en la mente como un destino, o, en el decir de Kant, una "necesidad"; si entre los actos repetidos se cuenta el de gritar, luego de haber aprendido de manera azarosa el niño su dominio a través del grito, su ejercicio se hará voluntario y terminará por corromperle; y si no duerme en una "cama dura", ¡pobre de él!, porque en lugar de parir al asceta futuro que debe, se habituará a la "comodidad", un remedo del demonio para el severo pensador de Königsberg, quien la considera "para el hombre peor que todos los males de la vida" (KANT, 2013, p. 55-69), nada menos. Incluso cuando postula que la disciplina no esclavice al alumno, su deseo sigue exhumando moralidad, si bien en este caso, perteneciendo aún a la educación "negativa", en cuanto tal no lo sea.

La parte mayor del proceso educativo la constituye, decíamos, la formación. No falta en ella su porción negativa, pues en su primera parte, la disciplinaria, se trata en lo esencial de impedir faltas, y la actitud del alumno durante la misma debe ser de sumisión plena y obediencia pasiva ante la legítima coacción del instructor. El resto de la formación, afirma Kant, es positiva, y "consiste sobre todo en el ejercicio de las facultades de su espíritu", lo cual requiere prescindir mientras sea posible del uso de instrumentos al objeto de "cultivar su habilidad natural". Sus partes son la instrucción y la dirección, y el alumno ya se vale de su capacidad de reflexión y de su libertad; sigue habiendo coacción, cierto, pero ésta es moral en lugar de mecánica, propia de la disciplina. Por lo demás, la educación positiva centra su esfera de actuación únicamente en la libertad, de manera análoga a como la negativa lo hacía en la naturaleza.

Con todo, en el desarrollo de las ideas kantianas la subdivisión entre lo físico y lo moral atraviesa tanto las fronteras por las que se distribuye el discurso pedagógico cuanto los conceptos en que se articula. Así, cuando toca el turno de la formación del espíritu, o del alma, la educación se desdobla en una "física del espíritu", o didáctica -escindida a su vez en 
libre y escolar, siendo la primera más liviana en tanto en la segunda ya aparece, y muy presente, el trabajo-, y en pragmática o moral, dedicada esta última a "moralizar" en vez de a "cultivar" al educando. Y cuando acto seguido se pasa a los fines de la educación, la vemos deambular entre la "cultura general de las facultades del espíritu", a fin de mejorar su habilidad y el perfeccionamiento, y la "particular"; y, en aquélla, tomar una doble dirección, "física" y "pasiva" de un lado, y "moral" de otro. En aquélla, los recursos básicos los constituirán el ejercicio y la disciplina, pero en ésta el alumno ya se guiará por lo que no ha habido hasta ahora y no dejará de haber a partir de ahora: las máximas, esto es, la vía subjetiva al deber. Deberá seguirlas, y al seguirlas obrará bien.

Incluso cuando ya se trate únicamente de la "cultura moral", una dimensión física no dejará de estar presente; la misión primera de aquélla consistirá en "formar un carácter", lo cual equivale a "obrar por máximas", tras lo cual se halla un rígido plan de actuación, de una forma más usual de disciplina, cuyo encanto estriba para Kant en evitar que al final del mismo la educación haya forjado una persona veleidosa en lugar de la persona moral buscada. Dos de los tres elementos constitutivos de dicho carácter, la obediencia y la veracidad, aparecen con su contrapunto de castigos cuando se incumplen, y entre ellos los hay morales pero también físicos; el tercero de dichos elementos, la socialidad, no se acompaña de su sombra punitiva, pero no nos parece imprudente colegir el destino del muchacho inamistoso o falso (KANT, 2013). ${ }^{17}$

Naturalmente, también en este ámbito aparece ese plus de moralidad que Kant debió evitar o, al menos, edulcorar. Aún nos las habemos con niños, o muchachos, y ya el trabajo aparece como una bendición para el hombre que será (KANT, 2013); las facultades inferiores del alumno merecen sin duda la atención del pedagogo, pero sólo en función de sus facultades superiores (KANT, 2013, p. 67); ya debe conocer los princi-

17 Recordemos que "decir la verdad" era para Plutarco (2002) el deber "más sagrado" a enseñar a un niño (op. cit., cap. 14C). 
pios del deber (KANT, 2013, p. 69); cuando aún no puede razonar sobre muchas cosas; ya es presa de una cultura moral, o sea, el niño/muchacho ya obra mediante máximas, porque una cabal distinción entre lo bueno y lo malo le ha sido inoculada a su tiempo (KANT, 2013, p. 72). En suma: ya debe obedecer el mandato del deber (KANT, 2013, p. 75).

La formación del carácter prosigue con la educación práctica. ${ }^{18} \mathrm{La}$ receta aquí pasa primero por "suprimir las pasiones"; es menester prevenir que "sus inclinaciones" se transformen en pasiones y habituarle "a pasar sin lo que se le niegue". "Soportar" es la clave: en esta fase de la vida del sujeto educarlo es impedir que las semillas de mal que anidan en su naturaleza puedan florecer como vicios o como deseos desordenados. Lo cual exige valor y temple por parte del educando. Resulta asimismo necesario prescindir de una compasión mojigata hacia sus semejantes en dificultades, por un lado, y hacer gala de firmeza en las decisiones y resolución en las acciones, por otro. Una promesa hecha, una intención explicitada son leyes para la voluntad, de cuya obediencia sólo exime el ser contrarias a la moral. El individuo tiene ahí un buen termómetro con el que medir la confianza en sí mismo.

Para formar el carácter en los niños, añade Kant, el tutor habrá de recurrir a "enseñar el deber mediante ejemplos y disposiciones". En primer lugar, los deberes de cada uno consigo mismo, como el de refrenar sus inclinaciones y caprichos, además de, por decirlo ahora en términos positivos, "conservar en su propia persona la dignidad humana"; luego, los deberes para con los demás, de lo que hay una señal que lo delatael sagrado respeto por el derecho de los hombres, y su práctica- y una garantía que lo reproducirá si se establece: "un catecismo del Derecho".

Ya adulto, el niño y muchacho que haya logrado entender tales enseñanzas y enseñado a su corazón a alimentarse placenteramente con ellas habrá asimilado un nuevo sistema de sentimientos, transformados de

18 Dicha educación empieza en la habilidad y prosigue en la prudencia antes de llegar a la moralidad, pero aquí el análisis, incluso somero, de ambas fases lo pasaremos por alto. 
hecho en valores, que purgará su corazón de las voraces dolencias éticas que sacuden a los hombres de su época, y afrontará la noria de deseos espurios y de perversos vicios en los que éstos atomizan su voluntad y extravían su existencia en un sinfín de actos inmorales: tantos, y tales, que el observador imparcial apenas dudaría en incluir el mal entre los genes del hombre; una presencia esa de la que Kant aceptaría a lo sumo sus semillas, erradicables sin embargo mediante la puesta en práctica del proyecto educativo esbozado hasta aquí. Éste le ayudaría a forjar una coraza de virtudes con la que derrotar al enemigo, al elevar "su corazón a los conceptos del deber y de la ley". Una tarea en la que encontraría un aliado postrero, la religión. Aun cuando para llegar a conocerla y absorber su fuerza debería partir justamente de otra ley presente en cada sujeto, su conciencia, de naturaleza moral. A través de ella llegaría hasta la religión, simplemente cuando al comparar las acciones con esa vara de medir, y salir negativo el resultado, quisiera hacer efectiva su condena: algo que sólo es posible cuando a "los reproches de la conciencia" se les "piensa como embajadores de Dios" (KANT, 2013, p. 79-89) ${ }^{19}$.

La semilla humana que la educación tomara en sus manos de la cuna para sacar de ella el ser moral contenido en la misma, la hemos visto transformarse a lo largo de estas páginas en el joven presente ante nuestros ojos, promesa profética del adulto rendido al deber que vendrá: profética, sí, porque su educación es la garantía en persona del resultado buscado. En el cuerpo sano y vigoroso del alumno de Plutarco, heredado de Platón, y legado a todo pedagogo futuro, hemos insertado un sistema de preceptos que empezaron por evitar los daños personales siendo aún infante y previniendo su comisión de faltas en grado de marcar su futuro;

19 Kant también habla del deseo, y también, naturalmente, lo filtra a través del deber. Aquí ahorramos el planteamiento kantiano al respecto a fin de no entristecer a los sentidos (y de no prolongar su ofensa a la mujer, una subespecie especial dentro de la especie humana $\mathrm{y}$, aunque a veces parezca la contrario, un objeto en realidad ausente de su educación, como bien nos recuerda en su Prólogo escrito por M. Fernández Enguita la edición de la Pedagogía kantiana aquí utilizada (KANT, 2013). 
que prosiguió capacitándole para las habilidades con las cuales proveer a sus necesidades para pasar después a la instrucción de sus facultades espirituales inferiores $\mathrm{y}$, finalmente, a la formación de las superiores. Y así lo vemos ahora, otro fruto histórico más del proyecto educativo de Juvenal condensado en la máxima mens sana in corpore sano, ${ }^{20}$ fuerte, disciplinado, capacitado, formado su carácter, respetuoso de sí mismo y de los demás, sensible, imaginativo, dotado de una gran memoria sobre la que basa su alta capacidad de entender, juzgar y razonar, y, en suma, la orientación de su conducta por la idea de deber. Etc.

¿Puede decirse humano este robot pedagógico? ¿Cómo es posible un ser así en entre los hombres, cómo sería un mundo lleno de seres como él? En primer lugar, su nacimiento es ya una disfunción teórica, pues supone tutores como él, esto es, situar al frente de la educación a sujetos que sólo debieran aparecer al final de la misma. ${ }^{22}$ De nuevo, pues, la teoría se ve, como tantas veces en el pasado, echando mano de seres excepcionales, tipo legislador roussoniano, antes de normalizarse. ¿Pero quién educó al educador? Lo que convierte la pregunta en decisiva, y no sólo en algo de importancia dentro del proceso educativo, es la militancia moral kantiana, que prácticamente arrolla la dimensión técnica del problema con la visceralidad ética de la solución presupuesta

20 Como es sabido, se trata del segundo hemistiquio de un verso que empieza así: orandum est ut sit (esto es, hay que rezar para tener [una mente sana en un cuerpo sano]), insertado todo él en una jaculatoria moral poblada de resabios platónicos y estoicos entre otros (Sátiras, X-356). Que la máxima devino un auténtico proyecto educativo lo atestiguan sus muchas citas por parte de pedagogos insignes; uno de ellos, Locke (1982) inicia con la misma precisamente sus Pensamientos sobre la educación.

21 Habría que calificarle, naturalmente, de algo así como estandarte del progreso en Kant, resultado de una idea que, metodológicamente, aún hoy parece alimentar el sueño de los afectos de profesión al mundo de la educación, puesto que constituye el adelantado de ese "componente utópico consustancial a todo proyecto educativo" (BEADE, 2011, p. 112) y que, al menos moralmente, parece olvidarse de los resultados del mismo.

22 En realidad, el problema de la elección del educador ya educado está presente en la doctrina pedagógica al menos desde Plutarco, quien por los criterios que establece para su elección muestra la magnitud del problema por resolver (Sobre la educación..., cap. 7B); con todo, dicha elección no reviste el dramatismo de la kantiana. 
por él. De ahí que, al menos en principio, la solución al enigma deba ser la misma de su homólogo socio-político en Rousseau: su "grande âme" (ROUSSEAU, 1962).

Un pedagogo ya guiado por la idea del deber, y permanentemente guiado por ella, como el hombre feliz de Solón recordado por Herodoto (2000) o el guardián platónico seleccionado para gobernar (PLATÓN, 2001), en realidad no tiene cura moral, porque su vicio de origen es intelectual, platónico por más señas: un pensamiento que construye explicaciones del mundo con ideas esencialistas, $\mathrm{y}$ tan frágiles que presionarlas en su configuración equivale a herir su talón de Aquiles, lo que hace saltar la coherencia del gran edificio construido cual si se tratase de un castillo de naipes. Platón, con toda su meticulosa elección de la persona del guardián por su carácter, que le hacía sobresalir entre los demás jóvenes de la sociedad, y con todo su planificado montaje de ilustración del mismo en las más hondas virtudes, cuando le ordena velar por el satisfactorio cumplimiento del programa educativo le enfatiza estar atento a no dejar introducirse la "novedad", porque con ella se inicia un proceso corruptor automático que daría al traste con toda la sociedade. ${ }^{23}$ Otro tanto sucede con la mayoría de las prescripciones de Kant, digno discípulo en esto también de Rousseau, quien antes lo fuera de Platón o Plutarco igualmente, pues estima que la aparición de un vicio en un momento inoportuno de la niñez es una bomba de tiempo contra el futuro sistema moral del educando. Y no se olvide que una de las consecuencias de una creencia como ésta consiste en prohibir el despliegue de las pasiones en aquél, vale decir, la mitad mayor de su género humano. Las pasiones son, pues, algo malo en sí, y la educación deberá refrenar las inclinaciones justo antes de degenerar en ellas, porque no habrá remedio de la enfermedad.

23 La República, 422a y 424d. Tampoco podrán tocar el oro o la plata, y no sólo porque ya los dioses los pusieron en sus almas, sino por su poder corruptor, sobre todo el de aquél; es decir, que el mal no reside en la voluntad, sino en el objeto, y que frente a su poder incluso la cuasi divina alma del guardián sucumbe (417a) (PLATÓN, 2001). 
Cuando se piensa con ideas como ésas la desesperación cunde incluso si se cree haber topado con la institucionalización de la esperanza en materia de educación, como era el instituto filantrópico de Dessau, fundado por Basedow en 1774. Kant puso en evidencia su infinita buena voluntad, esto es, su infame candor, al predicar sus objetivos con la fe del converso y hacer su apostolado en pro de la supervivencia del mismo, en el supuesto que bastaba un buen plan y una noble intención para garantizar el éxito. ${ }^{24}$ Y que nunca perdió por completo esa fe lo muestra la alusión a la necesaria fundación de institutos educativos, tan restrictivos en número dado que los pobres no debían entrar, ${ }^{25}$ presente en su pedagogía. Sólo que esos sanedrines morales, de llegar a existir, no sólo habrían debido cambiar la moralidad de sus ideas, sino la naturaleza intelectual de las mismas, para haber tenido éxito.

Con todo, supongamos entre nosotros, hecho y derecho, al educando kantiano ya adulto. Es muy posible que viéramos a Kaulbach (1978) practicar el arte oriental del vasallaje haciendo una genuflexión ante un personaje en el que muy probablemente habría visto realizado al sujeto legislador adivinado en el sujeto moral numénico: ¡y en medio de un sinfín de degradadas copias platónicas de la realidad ${ }^{26}$ ! Mejor aún entonces: supongamos una realidad social integrada mayoritariamente ${ }^{27}$ por tales educandos. ¿Cuáles serían los resultados?

Puesto que, presupuesta la consabida eficacia alemana, la producción

24 Fue en 1776, en un artículo redactado ex profeso con dicha intención (KANT, 2013).

25 No es que no creyese su educación útil o incluso necesaria, pero si no podían pagársela mejor que dedicaran su tiempo y energía a otras cosas, replicó Plutarco (op. cit., cap. 11D - E). Kant llega a una conclusión semejante por un camino en esencia no demasiado diferente.

26 A decir verdad, el flechazo kantiano por Platón empezó ya en la Crítica de la Razón Pura (KANT, 2005), cuando en su introducción enfatizó el valor de la idea platónica para el conocimiento.

27 Mayoritariamente en el sentido kantiano, se entiende, que en educación, como dijimos, reproduce el sistema restrictivo de su Filosofía del Derecho, pues son una ínfima minoría los que, además de ser libres e iguales, son también autónomos, la puerta de entrada a la ciudadanía. 
de robots morales en serie es posible, los pocos surgidos del anterior proyecto educativo se multiplicarán de inmediato, una vez mejorado el sistema con el rodaje. Por lo demás, en cada uno de los productos se ha concentrado toda la historia, incluida la futura, ya que se ha pasado desde la barbarie inicial, sabiamente contenida por los cuidados y la disciplina, hasta el sujeto que con el tiempo dará lugar a una sociedad civil -casiperfecta en un mundo lleno de tales sociedades civiles repobladas con individuos de alma cosmopolita. Ahora bien, si eso es así, ¿no son ellos $y a$ el mañana, no constituyen ya el material humano por venir, no son ya la realidad, o una parte de ella, de ese futuro que políticamente se antoja cada vez más próximo al ideal pero por siempre irrealizable?

Tanto si tales sujetos son los individuos del futuro, como si son tan solo los agentes del mismo, ${ }^{28}$ el ideal es ya en gran medida una realidad y su tiempo es el presente, o un futuro tan cercano que hasta se podrían contar las generaciones que faltan para completarlo con los dedos de una mano. Y tanto si la sociedad dominada por ellos es ya la sociedad civil republicana que la idea de una constitución republicana arrebató a los sueños y la modeló con el realismo de la necesidad, como si no, también la política de la libertad ha llegado ya o está a punto de hacerlo; porque, de lo contrario, la propia idea presente tras el plan se revelaría ahora no ya como un sueño, sino como una pesadilla, y nos hallaríamos en la contradicción impensada e insoluble de una sociedad constituida mayoritariamente por individuos libres guiados por la idea de deber pero tratados por los poderes públicos como sujetos no titulares de derechos e incapaces de reclamarlos. Algo así como los miembros de la Voluntad General - órgano legislativo - de Rousseau, guiados por la voluntad general - facultad legisladora - de cada uno, que aun siendo particular

28 Aún les falta, en efecto, al menos aparentemente, el aprendizaje político: pero cabe imaginar que ya encontraron al Kant de turno, desvestido de sus ropajes de pedagogo para vestir los de tutor político, y que les habría enseñado lo que la idea correspondiente les tiene deparado al respecto: con la probable lectura de su Filosofía del Derecho, o bien de su esquemático resumen, la Paz perpetua. 
prescribe lo mismo a todos ${ }^{29}$, transferidos desde la política a la sociedad y privados de su respectiva cuota de soberanía.

En definitiva, la incorporación al mundo real de los sujetos de la pedagogía kantiana no sólo adelanta la llegada del futuro mundo republicano y no sólo realiza la gesta que la razón, impulsada por la libertad, nunca dio por acabada, sino que, literalmente, la suplanta: la educación sustituye la política. La suplanta porque aporta como realidad el material humano, el sujeto, del futuro; y la suplanta porque muy probablemente, con individuos así-la versión moderna de los guardianes platónicos de los pobres no educados, que, en el creer de Kant, los obedecerán sin apenas rechistar una vez convertidos en libres e iguales, aunque no autónomos y, por ende, no ciudadanos -, la política perderá gran parte de su razón de ser, o más concretamente, de su razón coactiva de ser. Un giro éste en el que Kant, pareciendo imitar a Adam Smith, vuelve en realidad a quien, transformando la política en una técnica, la volatilizó en ella: su gran maestro Platón.

\section{Referencias}

BEADE, Ileana P. En torno a la idea de educación. Una mirada desde la reflexión pedagógica kantiana. Signos Filosóficos, Ciudad del Mexico, vol. XIII, n. 25, pp. 101-120, ene./jun. 2011.

HERMOSA ANDÚJAR, Antonio. El Problema de la paz en Kant. Palermo: Carlo Saladino Editore, 2012.

HERODOTO. Historias (Vol.1). Madrid: Gredos, 2000.

29 De lo contrario no habría esa "uniformidad" tan querida por Kant (2013, p. 33) y tan cara tanto a su tutor antiguo, Platón, como a su moderno, Rousseau: algo que ya Aristóteles despreciaba y que para Tocqueville o H. Arendt constituirá uno de los mayores peligros con los que las sociedades democráticas amenazan su futuro. Y en este caso, repárese bien, si los contenidos de tales voluntades particulares no fueran idénticos se caería en la pura anarquía. Moral al principio, pero directamente política a continuación. 
INNERARITY, Daniel. Libertad e historia en Kant, Revista Themata, Servilha, n. 4, 1987. Disponible en: http://institucional.us.es/revistas/ themata/04/06\%20innerarity.pdf Acesso en: 20 abr. 2014.

KANT, Immanuel. Pedagogía. Madrid: Akal, 2013.

KANT, Immanuel. Ensayos sobre la paz, el progreso y el ideal cosmopolita. Madrid: Cátedra, 2009.

KANT, Immanuel. Crítica de la razón pura. Madrid: Alfaguara, 2005 (A 316-317, B 372-374).

KANT, Immanuel. Filosofía de la historia. Madrid: FCE, 1981.

KAULBACH, F. Das Prinzip Handlung in der Philosophie Kants. Berlin: De Gruyter, 1978.

LOCKE, John. Pensamientos sobre la educación. Barcelona: Humanitas, 1982.

PLATÓN. La República. Madrid: Gredos, 2001.

PLUTARCO. Obras Morales y de Costumbres (Vol.1). Madrid: Gredos, 2002.

PORTER, Roy. The creation of the modern world. London a New York: Norton \& Company, 2001.

ROUSSEAU, Jean-Jaques. Du contrat social. Paris: Pléiade, 1962.

Data de registro: 02/07/2015

Data de aceite: $29 / 10 / 2015$ 